\title{
PENGEMBANGAN POTENSI DESA PILANG KECAMATAN MASARAN KABUPATEN SRAGEN MENUJU KAWASAN DESA WISATA
}

\author{
Solichul Hadi*), Muladi Wibowo**) \\ *) Program Pascasarjana UNIBA Surakarta, Surakarta, 57147 Indonesia \\ **) Fakultas Ekonomi UNIBA Surakarta, Surakarta, 57147 Indonesia
}

Email: muladiwib@yahoo.com

\begin{abstract}
Pilang village is a village in the district Masaran with batik and tourist potential which has not been excavated yet optimally by the government Sragen.

This research is a case study with a qualitative descriptive research method, this research aims are: I). To describe the picture potential of the District Pilang village Masaran Sragendalam District batik field, 2). To describe the picture potential of the District Pilang village Masaran Sragen in the field of Arts and Culture and 3). To formulate development strategies of local culture and art of batik village subdistrict Pilang Masaran Sragen towards Tourism Village.

Conclusions of the study: I). Pilang Rural Development as a tourist village of batik has been backed by local field potential major cultural arts group gong music, 2). Batik Pilang tourist village has great potential but has not been well managed and sustainable. 3 ). There is a potential gap in the rural area development batik Pilang with Kliwonan village. Suggestions for further study needs to be done by governments and stakeholders on issues of strategic areas of production, marketing, raw materials, involving regional and national stakeholders in order to improve the outlook of batik entrepreneurs, more specifically by conducting a strategic review which resulted in concepts and policies, in particular to increase tourist batik market and village Pilang nationally and internationally
\end{abstract}

Keywords: Tourism Village, Batik, Cultural Arts

\section{PENDAHULUAN}

Program Desa Wisata merupakan upaya pengembangan ekonomi kawasan yang bertolak dari potensi ekonomi, industri rakyat, khazanah seni budaya setempat yang dikemas dalam kegiatan pariwisata. $\mathrm{Di}$ Sragen, saat ini terdapat wilayah pedesaan yang menjadi klaster industri batik dan memiliki potensi untuk dikembangkan sebagai Desa Wisata.

Klaster industri batik Sragen meliputi tiga desa di Kecamatan Masaran yakni Desa Pilang, Kliwonan, dan Sidodadi serta tiga desa di Kecamatan Plupuh yakni Desa Jabung, Godongan, dan Pungsari. Desa-desa tersebut terletak di tepiansungai Bengawan Solo (sebagai informasi tambahan, dan dari Bappeda Sragen mencatat bahwa pada tahun 2010 kerajinan batik juga mulai tumbuh berkembang di desa Bukuran, Kec. Kalijambe).

Pada umumnya, perdesaan penghasilan bayik itu memiliki ciri khas ekonomi, sosial dan budaya yang memberikan warna dan corak masyarakat yang spesifik, yang berbasis pada : pertanian (budaya agraris), 
warisan budaya seni kerajianan batik, kerajinan rumah tangga lainnya, kegiatan keagamaan dan spiritual, budaya, mitos Joko Tingkir, serta pesona sejarah Sungai Bengawan Solo, maka batik Sragen sering disebut juga

Kerajinan Batik yang tumbuh di perdesaan tersebut di atas merupakan industri batik terbesar di luar klaser Surakarta (Solo) maupun Yogyakarta. Kuantitas produksi di kawasan ini merupakan kedua terbanyak di Jawa Tengah, setelah Pekalongan.

Klaster batik Sragen terdiri dari 85 UKM batik diperkirakan mampu menyerap 1.500 hingga 2.000 tenaga kerja. Secara keseluruhan, klaster batik sragen mampu menghasilkan antara 7.200 hingga 37.500 kodi batik per tahun, tergantung pada kapasitas tiap UKM dan jenis batik yang diproses. Jika dirupiahkan, kapasitas produksi klaster setara dengan Rp. 21,6 miliar s.d Rp. 30 miliar dalam setahun. Produk batik yang dihasilkan adalah dalam berbagai variasi produk, yakni : jarik, pakaian jadi, dan dengan beragam teknik batik : tulis, cap, printing, dan kombinasi di antaranya.

Batik yang dihasilkan dari sentra industri Batik Girli tersebut kemudian disetorkan ke pengepul atau juragan batik di Solo dan kota lainnya, maupun dijual langsung kepada pembeli yang singgah ke kota produksi milik perajin. Batik yang disetorkan ke pengepul / juragan biasanya masih dengan memasang labelmerk perajin. Tapi, banyak pula produk batik Sragen disetorkan tanpa label merk perajin, untuk kemudian dicantumkan label milik pengepul dan juragan batik besar di Solo dan kota lainnya.

Maka tak mengherankan bila masyarakat umum jarang mengetahui bahwa Sragen pun memiliki kawasan industri dan tradisi batik, kawasan yang perlu mendapatkan perhatian adalah Desa Pilang dan Desa Kliwonan, di Kecamatan Masaran, Kab. Sragen. Selama ini pemkab Sragen baru menggarap potensi kawasan batik di Desa Kliwonan, dengan nama pencitraan (brandmark) dari kawasan wisata tersebut adalah "Desa Wisata Batik Kliwonan".
Desa Pilang sebetulnya memiliki potensi yang sama dengan Desa, Kliwonan, namun memiliki kharakter UMKM yang berbeda dengan desa Kliwonan. Untuk itu melalui penelitian awal ini diharapkan merupakan penelitian pendahuluan untuk mellakukan studi kasus tentang potensi desa Pilang sehingga bisa mendapatkan perhatian dari PemKab Sragen untuk dikembangkan menjadi kawasan desa wisata, khususnya dibidang batik dan seni tradisi lokalnya.

\section{METODE PENELITIAN}

Penelitian ini dimaksudkan untuk mengidentifikasi potensi batik dan seni budaya dalam mendukung desa wisata Pilang Kecamatan Masaran Sragen, dalam rangka melakukan kajian pendahuluan dalam perumusan program dan kebijakan pengembangan desa wisata yang berkelanjutan.

Rancangan penelitian ini adalah kombinasi antara pendekatan deskriptip kualitatif, dll Metode pengumpulan data meliputi metode kuesioner (angket) dan dokumentasi, Focus Group Discussion (FGD), wawancara mendalam dengan metode analisis data analisis deskriptif. Lokasi penelitian desa wisata Pilang Kecamatan Masaran Sragen

\section{PENELITIAN TERDAHULU}

1. Penelitian Suwardi, dkk, tentang Pengembangan desabudaya nitriprayan kecamatan Kasihan Bantul sebagai alternative pemberdayaan wisata kulturaldiera otonomi daerah, 2006

2. Penelitian arif Budi Wurianto, tentang Alterbatif Model Pengembangan Pariwisata TerpaduKota Malang, tahun 2006

3. Penelitian Anastasia Eva, Rustina Untari, tentang Tahapan Pengembangan Produk Konveksi berbahan dasar batik pada klaster batik pasir putih Pekalongan tahun 2009

4. Penelitian Vicka Tamayadkk, Optimalisasi Kampung Batik dalam Mengembangkan 
Industri Batik Semarang di Kota semarang tahun 2010

5. Penelitian Santi Muji Umi, Kewirausahaan di Kalangan generasi muda bumiputra : Industri Kerajinan Batik Pekalongan abad Xx hingga awal abad XXI, 2011

6. Penelitian Ratna Khoiriunisa, Upaya pengembangan industry batik di Desa Gemeksekti kecamatan Kebumenkab,kebumen, 2012

7. Penelitian Arif Murtadlo,Upaya pengembangan usaha pengrajin batik Malangan Kab Malang, 2013

\section{HASIL DAN PEMBAHASAN}

\section{Gambaran Umum Desa Wisata Pilang}

Desa Pilang Masaran Sragen terletak di antara kaki Gunung Lawu dan Merapi Merbabu, secara topografis terbelah oleh Sungai Bengawan Solo yang berdampak pada perbedaan kharakter masing-masing wilayah. Desa Pilang mempunyai letak geografis yang unik, yakni berada di sepanjang aliran Sungai Bengawan Solo. Jarak dari Pusat Kota Sragen sekitar 13 kilometer, jarak tempuh tersebut didukung oleh infrastruktur yang baik, dan sebagai mana wilayah di Kabupaten Sragen lainnya, untuk menuju Desa Pilang pengunjung akan disuguhi areal persawahan yang luas dan subur.

Desa Pilang terletak di sebelah utara ibu kota Kecamatan Masaran dengan jarak 4 km dengan batas wilayah desa yakni Sebelah barat berbatasan dengan wilayah Kecamatan Plupuh, sebelah timur dengan Desa Pring Anom, sebelah utara dengan Desa KaranganyarKecamatan Plupuh dan sebelah selatan berbatasan dengan Desa Kliwonan.

Kondisi tanah di Desa Pilang pada dataran rendah dan sebagian persawahan tadah hujan. Luas wilayah Desa Pilang 1.691.070 ha, Penggunaan lahan terdiri dari : Tanah sawah sekitar : 163.000 ha, tanah kering sekitar 774.035 ha dan tanah pekarangan maupun bangunan sekitar 754.035 ha (data Desa Pilang 2014).
Desa Pilang berada pada ketinggian 100 $\mathrm{M}$ dari permukaan air laut, Curah hujan ratarata $24,25 \mathrm{~mm}$ per bulan dengan suhu udara rata-rata 27-29ㅇ C.Musim penghujan terjadi pada rentang Bulan Oktober sampai Bulan April, sedangkan musim kemarau berlangsung pada rentang Bulan Mei sampai dengan Bulan September.

Dari aspek Pemerintahan, Desa Pilang dipimpin oleh Kepala Desa dengan didampingi oleh 11 orang pamaong desa, yang didukung oleh 3 daerah kebayanan dan 7 dukuh dengan jumlah Rukun Tetangga sekitar 37, serta mimiliki perangkat pendukung BPD sebanyak 11 orang. (2014: data Desa Pilang diolah). Jumlah penduduk yang terdata di Kantor pemerintahan desa sebanyak 4.487 jiwa, yang terdiri dari penduduk laki-laki 2.195 dan Perempuan 2.292 jiwa, terhimpun dalam 1.265 KK. Dari aspek pendidikan sebanyak 1284 lulus SD, 1072 lulus SLTP, 572 lulus SLTA, dan lulusan PT sekitar 89. Sedangkan dari aspek agama yang dianut mayoritas beragama Islam, dimana yang beragama Katholik sebanyak 6 orang, Protestan sebanyak 14 orang serta beragama Hindu 5 orang. Berdasarkan jenis mata pencaharian mayoritas petani (511) dan buruh tani (341), selanjut adalah dengan profesi pedagang (275), PNS (65), Swasta (59) dan lainnya merupakan pekerja dengan ragam profesi seperti Polisi/TNI, penjahit, montir, sopir, tukang kayu/batu, guru dan pemulung.

\section{Desa Pilang Sebagai Desa Batik dan Wisata}

Bahwa sejak tanggal 1 Oktober 2009 batik Indonesia telah ditetapkan UNESCO sebagai salah satu warisan budaya dunia non kebendaan. Pengakuan UNESCO ini melekat pada teknik pewarnaan kain dengan pendekatan tradisional dengan teknik perintang warna. Disisi lain Batik di Indonesia juga secara historis mewakili khasanah teknik, simbol, dan budaya yang khas yang merupakan gabungan antara tradisi, gaya 
hidup, kepercayaan dan sekaligus bisnis (industri dan perdagangan).

Kegiatan usaha Batik di Desa Pilang diperkirakan telah berlangsung sejak 132-an tahun yang lalu, yang diawali oleh para pengrajin yang bekerja sebagai pembatik di lingkungan Keraton Surakarta Hadiningrat, Sehingga motif batik yang diproduksi masih memiliki keterkaitan dengan motif batik di Solo. Apalagi sesungguhnya sebagaimana sebagai mana disampaikan pengrajin Batik di Pilang bahwa, "Produksi batik saya ini ratarata untuk memenuhi kebutuhan dan permintaan pasar di Solo, setiap 2 minggu sekali saya mengantar produk saya ke Pasar Klewer kepada beberapa pedagang langganan saya "Kata Pemilik Batik Busana Asri.

Sehingga produk batik yang dihasilkan sampai dengan saat ini rata-rata mempunyai pakem Surakartan dengan proses pembuatan mayoritas memakai teknik cabut kombinasi. Ketrampilan membatik diperoleh turuntemurun dari pengrajian sebelumnya, dengan ciri motif yang dikembangkan di Sragen adalah Jawa-Hindu, motif burung, bunga, dan tumbuhan, dengan pilihan warna Sogan (coklat), biru, hitam, putih dan krem

Dengan demikian Batik bagi warga masyarakat Sragen merupakan salah satu warisan budaya. Hal ini sebagai mana disampaikan Bapak Sukino (2014) salah satu pengusaha batik, yakni : " Bagi kami batik bukan hanya sebagai mata pencaharian, namun bisa jadi merupakan bagi dari kehidupan kami, hal ini menjadi bagian dari kegiatan tak terpisahkan antara menggarap sawah dan membatik. Bagi pengusaha kecil seperti saya yang membatik berdasarkan pesanan, membatik diharapkan menjaga tradisi lelulur kami. :

Sehingga batik selain merupakan warisan leluhur yang mempunyai nilai seni tinggi pada prinsipnya telah menjadi salah satu bentuk mata pencaharian alternatif bagi warga desa Pilang. Tantangan utamanya adalah belum banyaknya regenerasi pembatik di Desa Pilang, sehingga lebih banyak para pembatik yang sudah tidak muda lagi. Hal ini sebagaimana disampaikan oleh pembatik (2014), " Gih mbatik niki biasanya kalau tidak garap sawah, tetapi yang batik gih (ya) hanya ini pak, sudah tua, yang muda lebih memilih kerja di pabrik atau ke kota "

Batik di Desa Pilang, pasca pengakuan UNESCO juga berdampak pada meningkatnya kapasitas produksi dan mampu menjadi salah satu faktor yang bisa mendorong pertumbuhan ekonomi di daerah, memberikan kontribusi terhadap Pendapatan Asli Daerah (PAD) yang cukup besar yang akhirnya dapat meningkatkan kesejahteraan bagi masyarakat terutama pengrajin/ pengusaha batik Sragen.

Keunikan lainnya kawasan Batik di Kecamatan Masaran, termasuk Batik desa Pilang adalah karena lekasi desa yang dekat dengan tepian Sungai Bengawan Solo, sehingga sering disebut sebagai komunitas Batik "GIRLI", Batik Pinggir Kali. Sentra kerajinan batik Sragen sendiri saat ini meliputi Desa Kliwonan, Pilang, Sidodadi Kecamatan Masaran, Desa Jabung, Gedongan dan Pungsari Kecamatan Plupuh serta Desa Bukuran Kecamatan Kalijambe.

\section{Potensi Desa Pilang Dalam Bidang Perbatikan}

Lokasi Desa Pilang, Desa Kliwonan dan desa Sidodadi berada di Kecamatan Masaran yang memiliki UMKM atau pengusaha penghasil batik khas Sragen. Desa Pilang merupakan daerah yang terdiri dari industry kecil yang memproduksi batik yang mayoritas menjual produknya diluar daerahnya, Di Sragen, untuk produk batik Desa Pilang di jual di Central Batik Sukowati, selain itu sebagian besar produk dikirim ke Solo, Yogya, Jakarta dan beberapa di jual keluar negeri. Di Desa Pilang terdaftar lebih kurang kurang lebih 28 pengusaha batik kelas menengah dan yang kecil.

Setiap pengusaha batik di desa Pilang dalam proses memproduksi batik paling sedikit memiliki 7 tenaga kerja dan paling banyak 60 tenaga kerja. Keberadaan kerajinan batik di Desa Pilang mampu menyerap tenaga kerja langsung sebanyak 
lebih dari 773 orang dari warga setempat dan sedikitnya 300 tenaga kerja tidak langsung (pembatik sanggan, marketing freelance, tukang gambar, kuli angkut, peracik pewarna alam dan lain sebagainya).

Tabel. 5.1

Potensi UMKM Batik di Desa Pilang berdasarkan Kapasitas Jumlah Tenaga Kerja

\begin{tabular}{|c|l|c|c|c|}
\hline \multirow{2}{*}{ No } & \multicolumn{2}{|c|}{ PERUSAHAAN } & \multicolumn{3}{|c|}{ JML TENAGA } \\
\cline { 3 - 5 } & & L & P & JML \\
\hline 1 & BATIK TULIS ALI MUKTI & 4 & 26 & 30 \\
\hline 2 & SUKINO & 2 & 5 & 7 \\
\hline 3 & SUHARTO & 2 & 20 & 22 \\
\hline 4 & HARNO HP & 5 & 10 & 15 \\
\hline 5 & SIDO MULYO & 3 & 40 & 43 \\
\hline 6 & BATIK MIRA & & 7 & 7 \\
\hline 7 & MUKTI ALI & 3 & 10 & 13 \\
\hline 8 & PERMADI & 4 & 20 & 24 \\
\hline 9 & Sekar Melati & 3 & 10 & 13 \\
\hline 10 & MITRA SARI & 3 & 20 & 23 \\
\hline 11 & BATIK SARTONO & 2 & 10 & 12 \\
\hline 12 & WAHYU TUMURUN & 4 & 10 & 14 \\
\hline 13 & BATIK HR & 15 & 10 & 25 \\
\hline 14 & MAWAR INDAH & 4 & 2 & 6 \\
\hline 15 & MAHMUDAH & 1 & 6 & 7 \\
\hline 16 & MARJUKI HADI & 7 & 10 & 17 \\
\hline 17 & CANTING MAS & 10 & 20 & 30 \\
\hline 18 & MANUNGGAL & 6 & 10 & 16 \\
\hline 19 & ABIMANYU & 3 & 47 & 50 \\
\hline 20 & DEWI RATIH & 7 & 73 & 80 \\
\hline 21 & DEWI BROTOJOYO & 7 & 58 & 65 \\
\hline 22 & MAHMUDAH & 3 & 12 & 15 \\
\hline 23 & DEWA DEWI & 6 & 2 & 8 \\
\hline 24 & PRANOTO & 10 & 15 & 25 \\
\hline 25 & BUSONO ASRI & 5 & 40 & 45 \\
\hline 26 & PUTRI LESTARI & 142 & 631 & 773 \\
\hline 27 & PUTRI LESTARI (versi b) & & & \\
\hline 28 & WAHYU TIGA JAYA & 53 & 38 \\
\hline & JUMLAH TENAGA KERJA YANG & 50 & 60 \\
\hline Tum & & 5 & 25 \\
\hline
\end{tabular}

Sumber (2014) : Hasil Penelitian (diolah)

Produksi Batik desa Pilang secara umum menggunakan desain motif batik tradisional, hal ini terjadi karena produksi batik desa Pilang lebih banyak merupakan produksi pesanan dan atau karakter home industri yang membuat batik sesuai dengan selera pasar. Hal ini sebagaimana yang disampaikan oleh Bapak Sukino (2014) " Produk batik saya rata-rata merupakan batik pesanan dengan motif tradisional, pertimbangannya lebih efisein produksinya, dengan screen yang sama kita bisa memproduksi banyak produk ". Kondisi ini bisa jadi karena kapasitas produksi 
masing -masing pengusaha batik belum banyak.

"Ya menurut saya, jika saya membuat motif baru selain membutuhkan biaya lebih, juga memiliki potensi kurang laku, atau tidak cepat laku, padahal saya membutuhkan dana cepat untuk membuat batik lainnya, " kata Sukino lebih lanjut. Begitu juga pendapat Pemilik Batik Busana Asri (2014), " Produksi batik saya kebanyakan merupakan batik pesanan yang setiap dua minggu saya kirim ke Pasar Klewer, dengan motif yang sudah jelas, produk saya yang cukup laku diantaranya adalah batik untuk bahan blangkon, ini saya buat terus menerus, Namun saya juga membuat beberapa motif kombinasi ".

Pemilik Batik Dewi Dewi (2014) menyampaikan lebih jelas yakni "Batik saya lebih banyak batik pesanan, dengan warna khas sogan, jadi gini mas, setiap pengusaha batik disini wis duwe pasar dewe dewe ( sudah punya pasar sendiri-sendiri), saya termasuk yang menjual saya ke sentral batik Sukowati "

Dengan demikian motif batik di Desa Pilang merupakan motif yang dibuat berdasarkan perkembangan dan selera pasar, khususnya pasar konsumen dan pasar di rantai pemasok Industri di Pasar-pasar tradisional maupun pasar modern. Potensi pengembangan pada motif lain didasarkan pada pesanan dari peminat, yang tentu saja merk dagang ada pada pemesan. Secara sisi industri, pengusaha batik lebih berperan sebagai produksen batik. Pada umum produk batik Pilang hanya terbatas pada produk sandang, namun beberapa UMK sudah mulai mengembangkan produk batik dalam bentuk lain seperti kerajinan tangan (tas, dompet dan perlengkapan pakaian), perlengkapan rumah tangga (household), batik kayu, batik kaca. Hal ini sebagaimana diuangkapkan oleh Sukino (2014) " kami juga tidak hanya membuat batik, namun sempat pula berinovasi membuat produk batik melalui ukir kayu, namun tidak mudah memasarkannnya, sehingga jika tidak ada pesanan, saya tidak akan membuat"

Sebagian besar produksi batik di Pilang dalam kegiatan produksi menggunakan teknologi tradisional, tujuanya adalah untuk menjaga kekhasan dan keunikan batik. Dalam perkembangannya pengusaha batik di Pilang juga mengembangkan pendekatan tradisional dan kombinasi antara cap dan tulis, serta ada yang menggunakan pewarna alam, produksi batik dengan cara kombinasi dilakukan untuk mensiasati pasar, agar lebih efisien dan sekaligus lebih cepat laku (harga) lebih murah, hal ini sesuai dengan penjelasan pemilik Batik Busana Asri (2014), " untuk produksi batik sing paling cepet (yang paling cepat) ya memakai cap dan tolet mas, Karena lebih murah dan cepat diproduksi, langsung bisa dijual harganya juga lebih mahal dari batik cap biasa, karena sebagai proses tetap menggunakan proses batik tradisional ".

Dengan pendekatan produksi kombinasi tersebut, mengakibatkan kemampuan produksi pengusaha batik di desa Pilang setiap bulan cukup tinggi (lihat tabel 5.2). Paling tinggi adalah produksi dari perusahaan Batik AR yang mampu memproduksi 9000 potong per-bulan, sedangkan yang paling rendah adalah Batik Mitra dan Mahmudah yang memproduksi batik sekitar 40 potong / bulan.

Tabel 5.2

Potensi UMKM Batik di Desa Pilang berdasarkan Kapasitas Produksi Setiap Bulan

\begin{tabular}{|c|l|c|}
\hline \multirow{2}{*}{ No } & PERUSAHAAN & JML PRODUKSI/BLN \\
\cline { 3 - 3 } & & (DLM PTG) \\
\hline 1 & BATIK TULIS ALI MUKTI & 400 \\
\hline 2 & SUKINO & 1400 \\
\hline 3 & SUHARTO & 200 \\
\hline
\end{tabular}




\begin{tabular}{|c|l|c|}
4 & HARNO HP & 300 \\
\hline 5 & SIDO MULYO & 2000 \\
\hline 6 & BATIK MIRA & 40 \\
\hline 7 & MUKTI ALI & 300 \\
\hline 8 & PERMADI & 100 \\
\hline 9 & Sekar Melati & 600 \\
\hline 10 & MITRA SARI & 500 \\
\hline 11 & BATIK SARTONO & 200 \\
\hline 12 & WAHYU TUMURUN & 3000 \\
\hline 13 & BATIK HR & 9000 \\
\hline 14 & MAWAR INDAH & 1000 \\
\hline 15 & MAHMUDAH & 40 \\
\hline 16 & MARJUKI HADI & 4500 \\
\hline 17 & CANTING MAS & 3000 \\
\hline 18 & MANUNGGAL & 3900 \\
\hline 19 & ABIMANYU & 4000 \\
\hline 20 & DEWI RATIH & 250 \\
\hline 21 & DEWI BROTOJOYO & 1500 \\
\hline 22 & MAHMUDAH & 70 \\
\hline 23 & DEWA DEWI & 2000 \\
\hline 24 & PRANOTO & 1500 \\
\hline 25 & BUSONO ASRI & 3000 \\
\hline 26 & PUTRI LESTARI & 120 \\
\hline 27 & PUTRI LESTARI (versi b) & 85 \\
\hline 28 & WAHYU TIGA JAYA & 5000 \\
\hline
\end{tabular}

Sumber (2014) : Hasil Penelitian (diolah)

Batik desa Pilang rata-rata memproduksi kain batik, jarik dan jarik lawasan dan sutra dengan teknik cabut warna, namun ada juga yang memproduksi jarik dengan tulis, maupun sutra dengan teknik batik tulis, serta sebagian kecil memproduksi sda produk jadi. Menurut pemilik Batik Dewa-Dewi (2014) "Saya membuat batik dengan teknik cabut warna karena biaya lebih murah dan cepat produksinya " begitu juga pendapat Sukino (2014) "Jarik cabut warna lebih efisien memproduksinya, serta waktu produksi juga lebih pendek."

Tabel 5.3

Potensi UMKM Batik di Desa Pilang

berdasarkan Bahan Baku dan Produk yang dihasilkan

\begin{tabular}{|c|l|l|l|}
\hline No & PERUSAHAAN & \multicolumn{1}{|c|}{ BAHAN BAKU } & \multicolumn{1}{|c|}{ PRODUK } \\
\hline 1 & $\begin{array}{c}\text { BATIK TULIS ALI } \\
\text { MUKTI }\end{array}$ & Kain mori & Kain batik cabut \\
\hline 2 & SUKINO & Katun & Jarik Cabut \\
\hline 3 & SUHARTO & Katun & Batik Cabut \\
\hline 4 & HARNO HP & Prima & Kain panjang+hem \\
\hline
\end{tabular}




\begin{tabular}{|c|l|l|l|}
5 & SIDO MULYO & Katun & Jarik Cabut \\
\hline 6 & BATIK MIRA & sutra ATBM+str twist & hem sutra \\
\hline 7 & MUKTI ALI & sutra & sutra cabut (bahan hem) \\
\hline 8 & PERMADI & Katun & jarik cabut \\
\hline 9 & Sekar Melati & Katun & jarik katun cabut \\
\hline 10 & MITRA SARI & primis & Jarik \\
\hline 11 & BATIK SARTONO & Katun & Jarik \\
\hline 12 & WAHYU TUMURUN & Katun & Jarik \\
\hline 13 & BATIK HR & katun, sutra & batik printing \\
\hline 14 & MAWAR INDAH & katun, ero & batik printing \\
\hline 15 & MAHMUDAH & sutra, mori, katun & bahan sutra tulis \\
\hline 16 & MARJUKI HADI & katun prima & Jarik Cabut \\
\hline 17 & CANTING MAS & katun & jarik lawasan sogo/batik \\
cabut
\end{tabular}

Sumber (2014) : Hasil Penelitian (diolah)

Dengan karakter produksi Batik desa Pilang dengan cara produksi kain batik, jarik dan jarik lawasan dan sutra dengan teknik cabut warna tersebut disisi lain berdampak pada munculnya masalah yang relatif sama di industri UKM, khususnya perbatikan, yakni, Daya saing produk rendah, akses pasar dalam dan luar negeri terbatas, kualitas SDM dan sikap entepreneurship terbatas, akses permodalan dan teknologi terbatas dan networking dan kemitrausahaan terbatas. Karena UMK hanya mengandalkan keahlian yang dimiliki dan kurang maksimal melakukan inovasi produk dan cara produksi.

\section{Potensi Desa Pilang Dalam Bidang Pariwisata}

Potensi utama wisata di Desa Pilang bertumpu pada dua pilar utama, yakni batik dan kesenian musik kentongan. Kedua aspek ini menjadi pilar pengembangan desa Pilang untuk dijadikan sebagai kawasan wisata pedesaan. Kawasan wisata pedesaan merupakan salah satu pendekatan pemberdayaan masyarakat untuk meningkat peluang potensi lokal untuk berkembang menjadi atraksi wisata yang menjadi tujuan wisatawan. Desa Pilang merupakan salah satu desa diwilayah Kabupaten Sragen yang memiliki sentra kerajinan batik, Pemerintah Kabupaten Sragen telah menetapkan desa Pilang bersama dengan desa Desa Kliwonan (keduanya di Kecamatan Masaran) serta Desa Pungsari, Desa Jabung, Desa Gedongan (ketiganya di Kecamatan Plupuh) 
sebagai kawasan kunjungan wisata (destinasi) berbasis ekowisata. Seni budaya yang berkembang di Desa Pilang meliputi Seni membatik, seni musik kentongan, seni gerabah rumah tangga, dan seni beladiri pencak silat.

Desa Pilang sebagai salah satu area destinasi wisata, sudah seyogyanya bila pilar utama batik dan kesenian kentongan harus dikembangkan secara berkesinambungan. Sehingga batik dan kentongan bisa menjadi atraksi wisata yang layak saji.

\section{Atraksi Wisata Batik}

Potensi Desa Pilang sebagai salah satu area destinasi wisata yang bisa dikembangkan dari potensi dan keberadaan industri Batik (Pilang 28 UKM) adalah dengan beberapa kegiatan dan atraksi wisata batik yang menarik, yakni :

a. melihat proses produksi dan belajar membatik, Pengunjung dapat mengamati proses pembuatan batik, mencoba menggoreskan canting batik, mencoba batik cap, dan bisa juga berbelanja batik dan souvenir

b. Mengunjungi Pembatik Tertua di Sragen. Sepeninggal Mbah Putri Towirejo (Pembatik sepuh Desa Pilang) yang wafat dua tahun lalu pada usia 104 tahun, perlu ada kegiatan berkunjung ke pembatik sepuh lainnya. Kunjungan ini sebagai bentuk penghormatan atas dedikasinya di dunia seni batik dan sekaligus untuk ngangsu wejangan bijak.

c. belajar membuat warna alam dari tumbuhan sekitar kita,

d. terdapat ada kelompok masyarakat penggiat kegiatan wisata belajar membatik.

e. Telah terlaksana Event Bersih Desa (pesta syukuran panen) yang dikemas dalam FESTIVAL DESA BATIK pada 2008. Event ini sangat menarik untuk dijadikan atraksi wisata tahunan desa.

f. Terdapat usaha kerajinan selain batik, yakni kerajinan sangkar burung ukir, gerabah alat rumah tangga dari tanah liat sawah dan kerajinan Suvenir Perca Batik.

g. Meningkatnya kunjungan dari berbagai kalangan, baik dari dalam maupun luar negeri. Mereka datang untuk berbagai keperluan, antara lain wisata belanja, studi wisata para pelajar, wisata belajar membatik, wisata fotografi alam, shooting film, obyek liputan budaya oleh media massa, studi banding perajin batik dari daerah lain, dll.

h. Desa Pilang sudah mulai dikenal agensi perjalanan wisata, media massa, peneliti, penggemar dan pemerhati batik di Indonesia.

Tabel. 5.4

Atraksi Batik di Desa Pilang

\begin{tabular}{|c|c|c|}
\hline $\begin{array}{l}\text { ATRAKSI \& DAYA } \\
\text { TARIK WISATA }\end{array}$ & AKTIVITAS WISATAWAN & DURASI \\
\hline Wisata Belajar Batik & $\begin{array}{l}\text { - } \text { Mengamati dan mencoba proses } \\
\text { produksi batik } \\
\text { - Belajar Membatik Singkat : } \\
\text { nyorek s.d. pewarnaan } \\
\text { - Belajar Membatik Khusus: desain- } \\
\text { nyorek-pewarnaan-pasar } \\
\text { - Belajar pewarnaan batik dng bahan } \\
\text { warna organik }\end{array}$ & $\begin{array}{l}40 \text { menit } \\
3 \text { jam } \\
7-10 \text { hari } \\
4 \text { jam }\end{array}$ \\
\hline Wisata Belanja Batik & $\begin{array}{l}\text { mengamati proses produksi batik } \\
\text { dan belanja batik dan produk } \\
\text { turunan batik }\end{array}$ & 1 jam \\
\hline $\begin{array}{l}\text { Event Bersih Desa/ } \\
\text { Festival Desa Wisata Batik }\end{array}$ & - karnaval tari batikan & 2 hari \\
\hline
\end{tabular}




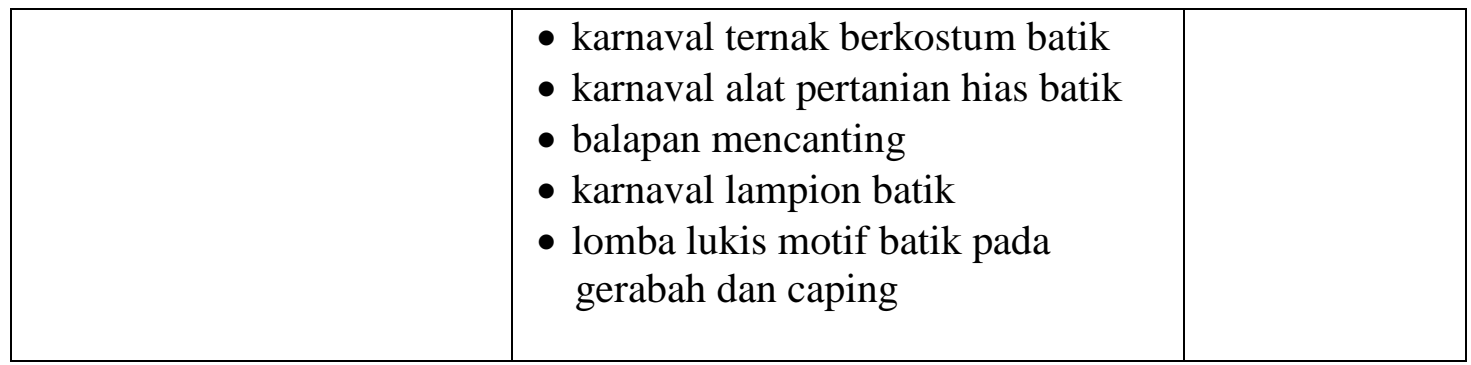

Potensi Desa Pilang sebagai salah satu area destinasi wisata juga didukung oleh keberadaan kelompok masyarakat yang mau berbagi peran dalam mengembangkan pariwisata dan batik di desa Pilang, yakni ; Forum Rembug Klaster dan Paguyuban Pengusaha Batik, Operator Paket Wisata Belajar Membatik 3 Jam, Grup Musik Kentongan Tua GUNO TENGORO, Grup Kesenian Nogoposo didatangkan dari Tanon, Grup Kesenian Rodat didatangkan dari Kalijambe dan Operator Event Tahunan Festival Desa Batik Pilang-Kliwonan yang diharapkan bisa saling berkolaborasi dalam pengembangan batik dan destinasi wisata desa Pilang,

Adapun potensi Desa Pilang dari aspek potensi kawasan yang bisa menopang terhadap potensi batik agar wisatawan merasa betah dan memiliki alternative minat kunjungan, antara lain ;

a. menikmati hamparan persawahan yang luas beserta kegiatan bertani (belajar menanam, belajar mengemudikan traktor sawah, menangkap belut, keong mas),

b. Belajar tanaman obat keluarga (TOGA) dan cara mengolahnya

c. bersepeda di atas tanggul sungai Bengawan Solo yang mengitari desa, menyaksikan kegiatan penyelam tradisional pencari pasir sungai, menikmati sun set/ sun rise dari atas tanggul bengawan solo,

d. terdapat spot fotografi outdoor yang unik yakni jembatan gantung di atas Bengawan Solo, rumah produksi batik, dan lain sebagainya.

e. Rumah khas kampung Jawa masih banyak. Beberapa di antaranya di Dukuh
Jantran Desa Pilang sudah dapat dipersiapkan menjadi homestay

f. Potensi terpendam Kesenian Rebana dan Nasyid (acapella bersyair ajaran agama Islam) yang dibawakan anak-anak TK/ SD, dan Taman Pendidikan Al Qur'an di Desa Pilang.

\section{Atraksi Wisata Kentongan}

Di kawasan Desa Wisata Pilang telah berkembang kesenian kentongan yang tergabung dalam Kelompok Kesenian Kentongan Tuwo Guno Tengoro, tepatnya di Dukuh Jantran Pilang. Di Jantran Pilang, di samping membatik, terdapat beberapa warga yang merupakan seniman lukis, seniman keroncong, campursari, karawitan, dan seni ukir sangkar burung.

Kelompok kesenian Guno Tengoro dibentuk pada 17 Oktober 2008 dan dimotori oleh kelompok tani Gemah Ripah Loh Jinawi dan Muda-Mudi Dukuh Jantran Desa Pilang, Kecamatan Masaran. Saat ini Kelompok Kesenian Tuwo Guno Tengoro dipimpin oleh Mulyanto Senggung dengan 25 personel pemusik.

Disebut musik kentongan tuwo (kentongan tua) lantaran perangkat kentongan yang digunakan telah berumur puluhan tahun. Selain itu sosok dan ukurannya pun istimewa, jauh lebih besar melebihi kentongan jaman sekarang.

Dalam penampilannya, Guno Tengoro mengusung sedikitnya enam kentongan tua (kasepuhan) sebagai alat musik utama dan dilengkapi seperangkat kentongan bambu (kanoman/ balungan) yang berfungsi sebagai pengisi variasi bunyi (isen-isen). Kentongan tersebut selanjutnya dimainkan dengan cara ditalu/ ditabuh dengan tongkat kayu dan bambu. Selain itu sebagai penghasil melodi, 
ditambahkan alat musik gamelan jenis demung depok atau terkadang saron.

Kentongan kasepuhan umumnya terbuat dari kayu keras seperti kayu nangka, trembesi, dan jati. Walaupun sebutannya adalah kentongan kasepuhan -sesepuh/ tetua-tapi para penabuh haruslah para pemuda berumur di bawah 30 tahun. Konon, jika penabuhnya sudah uzur, suara yang yang dihasilkan tidak terdengar gandhem. Wallahuallam.

Sajian Guno Tengoro umumnya adalah langgam Jawa dan lagu dolanan. Dikarenakan oleh latar belakang agraris para peronelnya, langgam utama yang disajikan dalam tiap pentasnya bercerita tentang siklus perjalanan padi dan petani.

Guno Tengoro ingin mengingatkan khalayak luas tentang perjuangan kaum tani di Indonesia dan menggugah rasa hormat terhadap tanaman padi. Langgam Jawa yang dilantunkan pun berkisah tentang masa-masa suilit pangan di era kolonial (Langgam Caping Gunung), suasana pesta panen di lumbung desa (Langgam Lumbung Desa), ditumbuk kaum ibu dan disajikan untuk makan keluarga (Langgam Lesung Jumengglung), dan kisah padi yang mampu memenuhi kecukupan pakan dan menyejahterakan masyarakat (Langgam Jangan Koro).

Dalam perjalanannya, Guno Tengoro kemudian menjadi ikon baru seni musik etnik di desa wisata batik maupun secara umum Kabupaten Sragen, serta memperkaya khasanah musik etnik di Jawa Tengah. Selain tampil untuk keperluan sajian atraksi wisata, Guno Tengoro telah berkali-kali mengikuti event kesenian di tingkat karesidenan Surakarta, propinsi Jawa Tengah, maupun internasional. Beberapa di antaranya adalah tampil di : Solo International Ethnic Music (2008), Event Seni Musik Rakyat di Mal Solo Square, atas undangan Pemerintah Propinsi Jawa Tengah dan Mataya Production (2008), Festival Grebeg Lawu, Karanganyar (2008), Gebyar Batik Sragen (2009), Event Budaya Jawa Tengah di Solo, atas undangan Bakorwil II (2010), Pesta Kesenian Rakyat di Pacitan
(2010), Pameran Keliling Museum Ronggowarsito di Sragen (2011), Karnaval Budaya dalam HUT propinsi Jateng (2011), Festival Lawang Sewu di Semarang (2011) dan lain sebagainya.

Dari observasi awal terhadap respon penduduk tentang program desa wisata, dapat dikatakan bahwa terjadi krisis kepercayaan terhadap program tersebut. Hal ini dikarenakan program itu dianggap tidak ada tindak lanjutnya. Warga pada umumnya sudah mulai bosan dengan sosialisasi yang menyangkut kelanjutan program pengembangan Desa WIsata. Sempat muncul tuduhan bahwa pembangunan Desa Wisata hanya akan menguntungkan sebagian kecil pengusaha batik saja, terutama pengusaha besar.

\section{Analisis Potensi dan Masalah Desa Pilang Sebagai Desa Batik dan Pariwisata}

Berdasarkan obervasi dan diskusi dengan warga masyarakat terhadap respon penduduk tentang program desa wisata, dapat dikatakan bahwa terjadi krisis kepercayaan terhadap program tersebut. Hal ini dikarenakan program itu dianggap tidak ada tindak lanjutnya. Warga pada umumnya sudah mulai bosan dengan sosialisasi yang menyangkut kelanjutan program pengembangan Desa Wisata. Sempat muncul tuduhan bahwa pembangunan Desa Wisata hanya akan menguntungkan sebagian kecil pengusaha batik saja, terutama pengusaha besar.

Disisi lain warga Desa Pilang berpendapat bahwa dalam pengembangan kawasan desa Wisata Pemkab Sragen tidak adil dalam menjalankan pembangunan desa wisata. Yang dimaksud dalam hal ini adalah perhatian yang diberikan Pemkab Sragen. Warga Pilang umumnya merasa bahwa desa Kliwonan lebih banyak diberi perhatian oleh Pemkab Sragen, antara lain dalam pembangunan infrastruktur jalan di Kliwonan lebih merata dan penataan lingkungannya lebih baik dibanding Pilang, tamu-tamu Pemkab lebih banyak diarahkan ke perusahaan batik di Kliwonan. Hal ini berdampak pada munculnya krisis 
kepercayaan warga sasaran program terhadap pengembangan desa Wisata, serta belum ada satu kesamaan persepsi di kalangan warga tentang apa yang dimaksud dengan Desa Wisata, potensi apa saja yang dapat dikelola bersama oleh warga, dan lain sebagainya.

Alternatif penyelesaian masalah antara lain; mensosialisasikan kembali program pengembangan Desa Wisata secara intensif, meyakinkan kembali bahwa program tersebut serius dilaksanakan. Targetnya adalah tumbuh satu persepsi yang sama tentang apa itu desa Wisata, mendatangkan tamu-tamu dan meningkatkan jumlah kunjungan ke desa wisata dan diarahkan secara merata di antara dua Desa Pilang dan Desa Kliwonan, menyusun program bersama antara warga dan pemerintah, menggali potensi penunjang lain di luar kain batik, misalnya gerabah (ada di dukuh Bibis), pemanfaatan kayu limbah (material ada di Desa Jati), wisata alam, dll serta perlu segera dibangun sarana pendukung dan infrastruktur di desa Pilangm misalnya Tugu signage sebagai penanda kawasan desa wisata batik, baliho-baliho iklan bertema batik/desa wisata batik, membenahi gedung koperasi Batik Girli dijadikan shelter, gunanya sebagai area parkir, menampung kedatangan pengunjung, pusat informasi, dan pos peristirahatan, perbaikan kios-showroom di rumah warga/ pengusaha batik untuk pemasaran langsung dan mempertegas ciri perkampungan batik dan melakukan penataan lingkungan, mengembangkan sistem pengelolaan sampah dan IPAL bersama.

Tabel. 5.4

Analisis Potensi Pengembangan Desa Wisata

\begin{tabular}{|c|c|}
\hline Analisis & Pandangan masyarakat \\
\hline Kekuatan & $\begin{array}{l}\text { - Potensi pengrajin dan produk batik yang dihasilkan } \\
\text { baik dalam hal jumlah, keanekaragaman, mutu dan } \\
\text { desain sangat variatif. } \\
\text { - Sudah terdapat Show Room ataupun Art Gallery batik } \\
\text { dan garmen batik yang cukup banyak } \\
\text { - Produk mulai dikenal baik secara nasional maupun } \\
\text { internasional. } \\
\text { - Kehidupan khas pedesaan dengan panorama alam } \\
\text { hamparan sawah dan ladang yang dikerjakan secara } \\
\text { tradisional } \\
\text { - Potensi Bengawan Solo yang mempunyai sejarah } \\
\text { panjang dan dikenal di Dunia } \\
\text { - Memiliki obyek ziarah berkaitan dengan Bengawan } \\
\text { Solo dan Sejarah Raja-Raja dari Kerajaan Pajang } \\
\text { yaitu Makam Ki Kebo Kenongo dan Makam Sultan } \\
\text { Hadiwijoyo } \\
\text { - Atraksi Wisata dan Seni Budaya Larung Ageng } \\
\text { Gethek Joko Tingkir yang dilaksanakan setiap tahun } \\
\text { dari Pasanggrahan Langenharjo Sukoharjo hingga } \\
\text { sampai di Makam Butuh Kecamatan Plupuh } \\
\text { Kabupaten Sragen. } \\
\text { - Jarak antara Desa Wisata Batik Kliwonan dengan } \\
\text { Museum Sangiran yang cukup dekat (15 km) } \\
\text { sehingga dapat menjadi paket wisata yang potensial }\end{array}$ \\
\hline Kelemahan & $\begin{array}{l}\text { - Kondisi jalan di dalam perkampungan belum } \\
\text { seluruhnya baik. } \\
\text { - Akses transportasi umum yang menuju Desa belum } \\
\text { ada } \\
\text { - Sarana informasi dan komunikasi yang masih kurang }\end{array}$ \\
\hline
\end{tabular}




\begin{tabular}{|c|c|}
\hline & $\begin{array}{l}\text { memadai, salah satunya karena belum masuknya } \\
\text { jaringan telepon kabel. } \\
\text { - Tingkat kesadaran masyarakat akan pentingnya } \\
\text { pengembangan kepariwisataan masih rendah. } \\
\text { - Penataan Show Room/Art Gallery sebagian besar } \\
\text { masih belum baik. } \\
\text { - Terbatasnya dana pengembangan kawasan wisata di } \\
\text { Desa Wisata } \\
\text { - Sumber daya pengusaha batik yang masih minim } \\
\text { pengetahuannya tentang manajemen perusahaan } \\
\text { terutama promosi penjualan. }\end{array}$ \\
\hline Peluang & 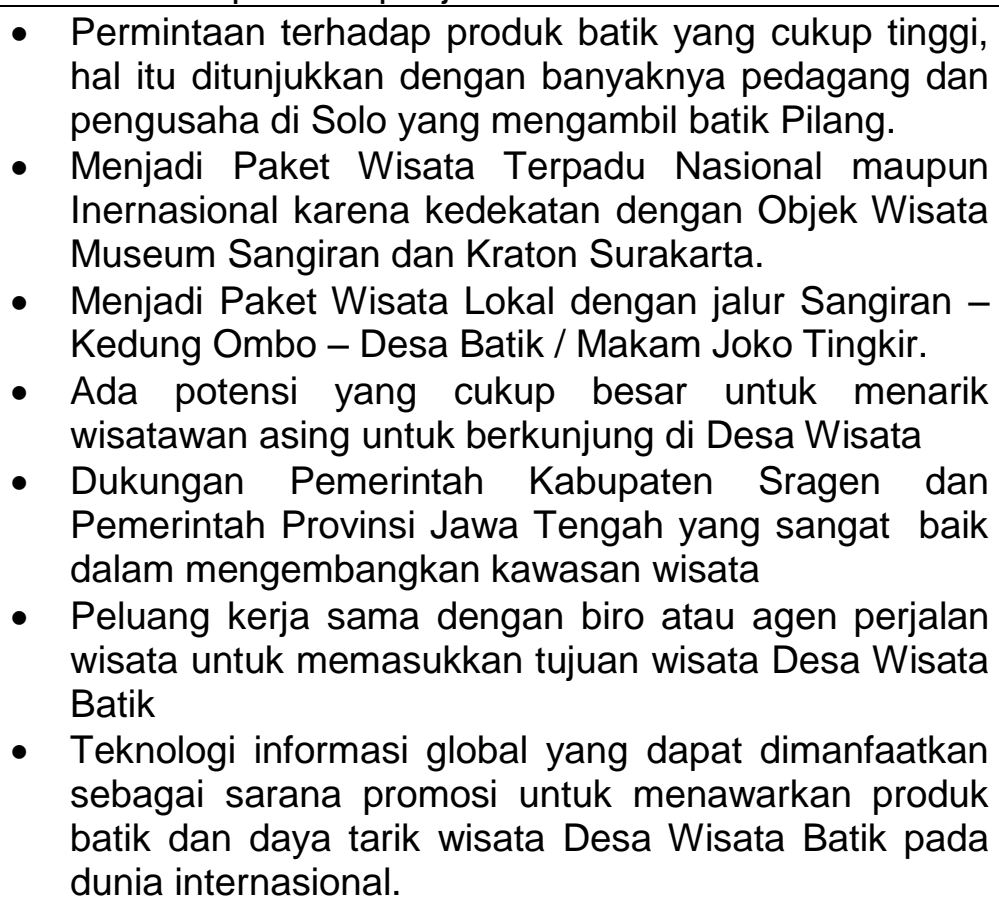 \\
\hline Hambatan & 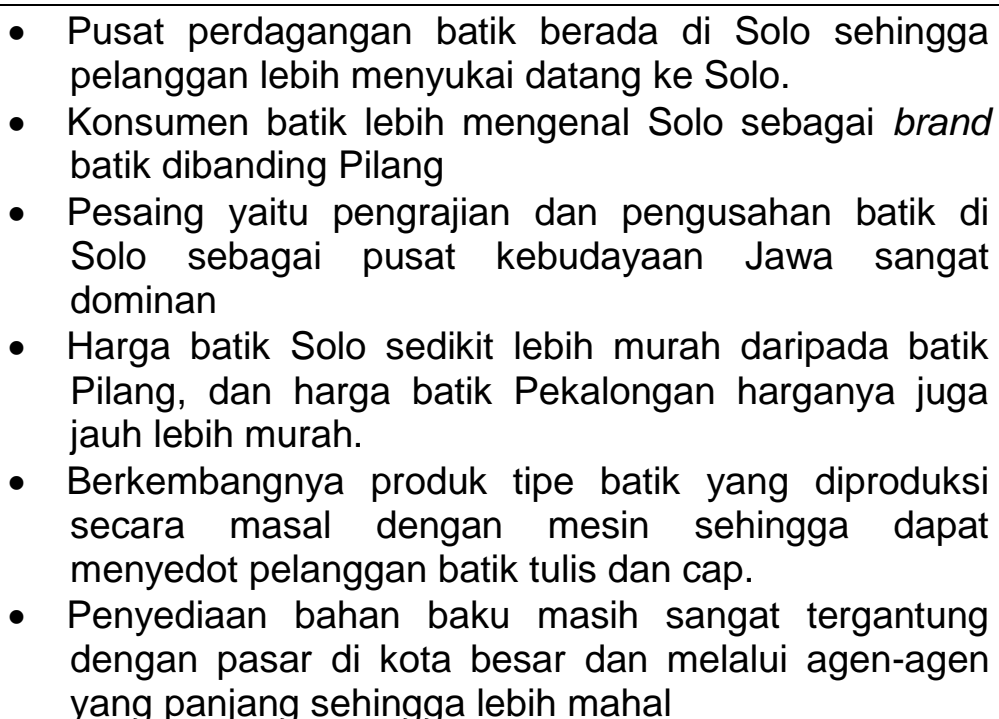 \\
\hline
\end{tabular}

Hasil FGD menunjukan bahwa Desa Pilang sebagai bagian dari kawasan wisata batik yang diharapkan menjadi unggulan oleh pemkab Sragen perlu diambil langkah bersama antara warga dan pemkab, antara lain :
1. Warga desa jangan malu-malu menampilkan orisinalitas tradisi dan aktivitas kesehariannya. Tradisi, kebudayaan, cara hidup, dan aktivitas keseharian mereka dapat dijadikan atraksi wisata untuk dijual kepada para turis. 
2. Perlu dibuat paket wisata yang memuat atraksi-atraksi wisata berupa aktivitas keseharian masyarakat tersebut. Dapat pula menyelenggarakan event kesenian di titik-titik/ lokasi strategis untuk membuka ruang berkumpul publik baru.

3. Perlunya menawarkan paket wisata belanja batik yang di dalamnya memuat atraksi proses pembuatan batik dan edukasi sejarah batik, praktek membatik, hingga belanja batik murah --langsung dari perajin tradisional. Paket life in homestay memuat atraksi, berkeliling kampung dengan berjalan kaki, sepeda kayuh atau bisa juga dengan ATV (All Terrain Vehicle - motor beroda 4 untuk offroad), atraksi belajar membatik, atraksi membuat makanan tradisional-kuliner, atraksi bertani di sawah-berkebun-beternak ikan, dll.

4. Perlu segera dilakukan penataan lingkungan dan penataan tempat usaha yang sekaligus menjadi rumah tinggal para perajin.

a. Penataan lingkungan dititikberatkan pada kebersihan lingkungan kampung, sarana dan prasarana sanitasi yang memadai.

b. Penataan tempat usaha dan rumah tinggal dititikberatkan pada penataan dan pembenahan ruang produksi, agar lebih nyaman bagi wisatawan untuk mengamati tahapan pembuatan batik dan sekaligus mempraktikkannya. Sirkulasi udara, kecukupan cahaya masuk agar dibenahi untuk memudahkan pengambilan gambar/foto/ dokumentasi. Perlu ada penataan ruangan untuk menampilkan produk di bagian depan rumah/ show room sederhana.

c. Ketersediaan sarana toilet yang baik dan air bersih baik di lingkungan kampung maupun tempat usaha/ rumah tinggal perajin yang dikunjungi.

d. Mengkondisikan desa sebagai pusat pembuat batik dengan menampilkan ornamen batik yang ditata sedemikian rupa di bagian depan rumah perajin/warga agar terlihat oleh pengunjung yang melintasi ruas jalan kampung. Penjemuran kain batik dalam hal ini masih diperbolehkan untuk dilakukan di depan rumah -akan memunculkan kesan perkampungan batik. Juga perlu didirikan show room yang berfungsi kios aneka macam produk batik di bagian depan rumahjuga diusahakan terlihat dari jalan raya. Fungsinya untuk memamerkan produk batik dan sekaligus menarik calon pengunjung untuk singgah dan membeli.

e. Fasilitas umum masih kurang misalnya warung makan, rest area, transportasi.

5. Produk batik yang ditampilkan/ dijualbelikan perlu dilengkapi tell story yang menjelaskan motif, sejarah produk tersebut, saran bahwa paling tepat di acara apa saja, dan lain-lain

6. membagi saham/permodalan dengan desa dalam hal pengelolaan paket wisata

\section{KESIMPULAN}

Berdasarkan studi pendahuluan tersebut dapat diambil kesimpulan yakni 1). Pengembangan Desa Pilang sebagai desa wisata batik telah didukung oleh potensi lokal bidang seni budaya utamanya kelompok musik kentongan, 2). Desa wisata Batik Pilang memiliki potensi yang besar namun belum dikelola secara baik dan berkesinambungan. 3). Terdapat kesenjangan potensi pengembangan kawasan batik di desa Pilang dengan desa Kliwonan. Saran perlu dilakukan kajian lebih lanjut oleh pemda dan stakeholder terhadap isu-isu strategis bidang produksi, pemasaran, bahan baku, yang melibatkan stakeholders regional dan nasional agar meningkatkan cara pandang pengusaha batik, Lebih khusus lagi dengan melakukan kajian strategis yang menghasilkan konsep dan kebijakan, khususnya untuk meningkat pasar batik dan wisata desa Pilang secara nasional dan internasional. 


\section{DAFTAR PUSTAKA}

Agus Salim (2006), BANGUNAN TEORI, Metodologi Penelitian untuk Bidang Sosial, Psokologi, dan Pendidikan, Penerbit Tiara Wacana, Edisi Kedua, Yogyakarta.

Anderson,David R et.al.(1984), STATITICS FOR BUSINESS AND ECONOMICS, West Publishing Company, NY-LA-San Francisco.

Badaracco Jr.,Joseph L.(1991), THE KNOWLEDGELINK, How Firms Compete Through Strategic Alliance, Harvard Business School, Boston.

Berta Bekti Retnawati, A. Eva Maria Soekesi (2010), Model Supply Chain Produk Usaha Kecil (studi Kasus Pada Kampoeng Batik Laweyan Surakarta), Semarang:UNIKA Soegijapranata

Bisri, Slamet Riyadi (2004), PENGARUH STRATEGI KEUNGGULAN KOOPERATIF TERHADAP KEMAMPUAN BERSAING PERUSAHAAN KECIL DAN MENENGAH DALAM PEMASARAN INTERNASIONAL (Suatu Studi di Kota Bandung), disertasi, Universitas Padjadjaran sandwich dengan Phillips University Marburg, Bandung.

Chirchill,Jr,Gilbert A.(' 1988), BASIC MARKETING RESEARCH, The Dryden Press.,Chicago.

Habeiby, Handry(2007) system informasi distributor Batik di Kampung Batik Laweyan Solo berbasis Web, Surakarta:UMS Surakarta, http://etd.eprints.ums.ac.id/I2266/

Ja'far Hafsah (2005), KEMITRAAN , Pengembangan UMKM, Penerbit Jakarta.

Khasanah, Imroatul (2008) Pengaruh TI pada Strategi Pemasaran Internasional terhadap Pangsa Pasar Luar Negeri Semarang : UNDIP, http://eprints.undip.ac.id//427 I/

Koentjaraningrat (1985), METODE METODE PENELITIAN MASYARAKAT, Penerbit Gramedia, Jakarta.

Murni Sari (2010). Strategi Produksi Bersih untuk Meningkatkan Manajemen Lingkungan pada Industri Skala Kecil :Studi Kasus Industri
Kerajinan Batik"K”Solo, Surabaya :ITS http://digilib.its.ac.id/detil.php?id=I I57:Master Moh. Sibaweh (2009) Pengaruh Faktor Psikologis, Sosial dan Bauran Pemasaran Terhadap Keputusan Pembelian Batik di Pasar Grosir Setono Pekalongan. Semarang:Universitas Negeri Semarang

Parlindungan, Walden Jan (2008), Strategi Pemasaran PT Mustika Ratu Tbk dalam upaya Memasuki Pasar Internasional, Jakarta : UI http://www.digilib.ui.ac.id/opac/themes/libri2/d etail.jsp?id=74974

Putri Yani Dwi Nurul Safiah, (2010), Analisis Keberadaan BTC dan PGS terhadap Mobilitas Perdagangan Pasar Batik Klewer, Surakarta : UMS, http://etd.eprints.ums.ac.id/86/4/

Siswanti (2007), tentang Faktor - Faktor Yang Mempengaruhi Perkembangan Industri Batik Di Kawasan Sentra Batik Laweyan Solo, Semarang :Digilab Fakultas teknik. Universitas negeri Semarang, diunduh diportal Garuda, 20 maret 2012

Sudantoko, Djoko (2004) Pemberdayaan Industri Batik Skala Kecil di Jawa Tengah (studi kasus di Kabupaten dan Kota Pekalongan, Semarang: UNDIP ,http://eprints.Undip.ac.id /24003 